\title{
Centrifugation of adipose tissue aspirate causes endothelial cell enrichment
}

\author{
Dani Lutfi ${ }^{1}$, Lukas Leitner ${ }^{2}$, Maximilian Zeyda ${ }^{2,3}$, Thomas Stulnig ${ }^{2}$, Christian F Singer ${ }^{1}$ and Edvin Turkof ${ }^{1}$ \\ ${ }^{1}$ Department of Obstetrics and Gynecology, Medical University of Vienna, Vienna, Austria \\ ${ }^{2}$ Christian Doppler-Laboratory for Cardio-Metabolic Immunotherapy at the Dept. of Medicine III, Clin. Div. of Endocrinology and Metabolism, Medical University of \\ Vienna, Vienna, Austria \\ ${ }^{3}$ Department of Pediatrics and Adolescent Medicine, Clin. Div. of Pediatric Pulmonology, Allergology, and Endocrinology, Div. Medical University of Vienna
}

\begin{abstract}
A recent study demonstrated that centrifuging fat causes a density gradient where progenitor cells (ASCs) show a higher concentration in the lower part of the fatty cylinder. Furthermore, it was shown that fat grafts of this part have a higher survival rate and it was hypothesized that this is due to higher concentration of ASCs. Since ASCs are only a part of the stromal vascular cell fraction, we hypothesized that the main reason for a higher take of autologous fat grafts might not solely be due to ASCs but other cell types as well. We aimed to verify which cell types exactly are concentrated in the stromal vascular fraction of the lower part of the fatty cylinder. Human adipose tissue from 10 female patients was subjected to a washing procedure to remove blood cells and cells were mechanically released to assure homogeneous sample size and quality. Subsequently, samples were divided into three groups. 1) Sedimentation, 2) Mild centrifugation, and 3) Harsh centrifugation. Stromal vascular cells (SVCs) were isolated by filtration and centrifugation from each processed cylinder. SVCs were simultaneously stained and analyzed by flow cytometry to determine the cell types present. Our results show that out of all stained cells in the stromal vascular fraction, only endothelial cells were enriched in the lower part; remarkably, ASCs were not enriched, in contrast to results of previous studies.
\end{abstract}

\section{Significance statement}

Our study shows that centrifugation of fat tissue grafts causes endothelial cell enrichment in the lower part of the fatty cylinder and in contrast to results of previous studies ASCs were not enriched.

After the discovery of ASCs in fat tissue grafts their potential was made accountable to positively enhance the take rate of fat grafts. Furthermore, studies showed that centrifugation of fat grafts can cause density gradients with increased cell count numbers of ASCs.

Our study could reveal that not ASCs but endothelial cells are accountable for the enhancement of the take rate of fat grafts.

\section{Introduction}

The restoration or augmentation of soft tissue defects caused by trauma, congenital abnormalities or cancer surgery is one of the most important goals in plastic surgery. Numerous techniques were invented to restore defects of different origin. Amongst a variety of procedures, the technique of free autologous (body's own) fat transfer stood out due to low complication rates and simple implementation. The first reported case of autologous fat transfer was in 1893 when Neuber re-implanted upper arm fat tissue to correct a depression in the face [1]. Only two years later, in 1895, Czerny performed the first breast reconstruction using a large lipoma from the dorsal flank [2].

With a rising interest in synthetic implants and after a study in the 1950s showed minimal graft survival of autologous fat grafts oneyear post-transplantation due to technical problems with harvesting, lipotransfer became less and less common [3].

In 1974, Giorgio and Arpad Fischer, two Italian surgeons, invented the "dry" liposuction technique using a hollow suction cannula. In the same decade, Kesselring and later Schrudde described similar techniques using sharp curettage to remove fat $[4,5]$.

However, in 1978, it was Illouz's striving for the efficiency and accuracy of a minimally invasive procedure, in combination with tumescent anesthesia, that brought a milestone to what in now commonly wellknown as liposuction. He removed fat cells from small port incisions using a blunt hollow suction cannula and high-powered vacuum suction [6].

In the early 1990's, Coleman successfully began grafting fat to the face and later to the body and breast, thereby defining Coleman's technique, which has been developed through years of practice and became a standard procedure in the plastic surgery community [7].

However, not every physician performing lipofilling follows the "Coleman's technique". The wide range of options for gaining and processing fat tissue with almost identical outcomes prevents the determination of a standard operating procedure (SOP).

For all issues concerning the search for the optimal technique, well-conducted scientific studies are strongly demanded [9]. Through refining liposuction techniques, greater amounts of harvested fat became available and hence the demand rose to augment buttocks or breasts with large-volume lipofillings.

Correspondence to: Dani Lutfi, Franz-Josefs-Kai 43/2/15, 1010 Vienna, Tel: 00436608366680; E-mail: Dani.lutfi@gmail.com

Key words: Adipose derived stem cells, ASC, lipofilling, endothelial cells, endothelial cell enrichment, take rate enhancement, fat grafting

Received: March 12, 2018; Accepted: March 23, 2018; Published: March 31, 2018 
In 2007, The American Society of Plastic Surgery (ASPS) reversed its 20 -year moratorium on fat grafting to the breast, realizing that if properly performed, the procedure is effective and poses no significant risk, yet underlining the potential volume limitation caused by the likelihood of necrosis and cyst-formation [8].

Currently, autologous fat transplantation can be considered a minimally invasive surgical technique with low morbidity, and the choice of method is mainly based on anecdotal evidence. Since the introduction of autologous fat grafts, many studies examining ways to enhance graft take have been published [10-12].

In 2001, P. Zuk first discovered the presence of a new population of adult stem cells in the stromal vascular fraction (SVF) from liposuctioned adipose tissue. Initially, these cells were termed Processed Lipoaspirate Cells or PLA cells, their nomenclature later changed by The International Fat Applied Technology to "adipose-derived stem cells" or ASCs [13].

After discovering the presence of ASCs [13], many studies have been undertaken to examine the effect of ASCs on survival rates during fat transplantation [14-17].

It was shown that ASCs have angiogenic and antiapoptotic potential, express synergistic proangiogenic growth factors [18], and enable better vascularization of fat grafts, thereby reducing the probability of necrosis and adipocyte resorption [14,17].

In 2001, von Heimburg grafted a collagen matrix seeded with ASCs and preadipocytes in rats and observed that ASCs differentiated into mature adipocytes [19].

Soon, the industry created various techniques to enable ASC enrichment in fat transfer procedures which all, until now, were very cost-intensive and time consuming [20-22]. Therefore, this procedure did not significantly spread in the Plastic Surgery community. In contrast to these laborious and expensive procedures, during a congress in Verona in September 2010, Coleman first claimed that simple centrifugation creates graded densities of fat grafts [23]. According to a ten-week study, greater percentages of the highest density fractions of lipoaspirate persist over time as they contain more progenitor cells (ASCs) and increased concentrations of several vasculogenic mediators (such as VEGF, PDGF, and adiponectin) than lower density fractions [23]. These findings have a special importance as they enable ASC enrichment in a relatively short amount of time with nearly zero additional costs. As the SVF of adipose tissue consist of different cell types, we hypothesized that centrifugation of fat aspirates might not lead to ASC enrichment alone and planned the present study to investigate which cells exactly are concentrated in the lower part of the fatty cylinder.

\section{Patients and methods}

\section{Patients and sample collection}

Human adipose tissue from 10 random female patients undergoing breast reconstruction by lipofilling at the Medical University of Vienna, Department of Obstetrics and Gynecology, aged between 38 and 62, was aspirated with a $10-\mathrm{ml}$ syringe and a blunt cannula with a diameter of $2 \mathrm{~mm}$ and twelve holes with a diameter of $1 \mathrm{~mm}$. The lipoaspirate from each patient was then divided into two main groups: non-washed (A) and washed (B) and three subgroups (1-3): sedimentation, mildcentrifugation and harsh-centrifugation.

\section{Non-Washed Group A}

The lipoaspirate was placed in $10 \mathrm{ml}$ syringes for subsequent separation into subgroups 1-3.

\section{Washed Group B}

The lipoaspirate was placed in a strainer above a sterile jar and rinsed with $30 \mathrm{ml}$ of sodium chloride in order to remove unnecessary fibrin particles. This process was repeated three times. The filtered fat tissue/sodium chloride solution was collected with $50 \mathrm{ml}$ syringes and placed upside down for 10 minutes creating a separation of the two phases (filtered fat tissue/sodium chlorine). After dispatching of the lower phase (containing unnecessary components such as blood, fluid, and fragmented cells) by pushing the plunge a homogenous sample was produced. After washing was completed, aspirates were decanted into three $10-\mathrm{ml}$ syringes so that three equally filled samples were obtained.

\section{Sedimentation}

1: The lipoaspirate was placed in $10 \mathrm{ml}$ syringes in an upright position for $30 \mathrm{~min}$ at room temperature $\left(23^{\circ}\right.$ Celsius $)$ creating two visual phases.

\section{Centrifugation}

2: Mild centrifugation group, where syringes were centrifuged for one minute at room temperature: $188 \times g(500 \mathrm{rpm})$.

3: Harsh centrifugation group, where syringes were centrifuged for three minutes at room temperature: $1,228 \times g(3,100 \mathrm{rpm})$ according to the Coleman protocol $[24,25]$. The centrifugation resulted in a visual separation of two different phases with the aqueous phase at the bottom and the tissue phase above it. The tissue phase (fatty cylinder) itself can be separated in half in an upper phase and lower phase.

\section{Isolation of the stromal vascular cell (SVC) fraction}

The lower and the upper halves of the tissue phase were collected by carefully pushing the plug into the syringe. Aspirates were incubated with 2 volumes of $50 \mathrm{U} / \mathrm{ml}$ DNase I (Sigma-Aldrich) and Collagenase I (Worthington, Lakewood, NJ) at a concentration of $2 \mathrm{mg} / \mathrm{ml}$ for 60 minutes at $37^{\circ} \mathrm{C}$ and SVCs were isolated by filtration, centrifugation, and red blood cell lysis as described previously [26].

\section{Flow cytometry}

SVCs were simultaneously stained with the following fluorochromeconjugated mAbs: CD45-PE-Cy7, CD34-PerCP, CD73-PE, CD105FITC, and CD90-APC (all BD Biosciences) according to standard procedures and analyzed on a FACSCanto II using the FACSDiva Software (BD Biosciences).

\section{Statistics}

Using the general linear model calculation in IBM SPSS 22 software, multifactorial ANOVA was performed. The factors analyzed were centrifugation (sedimentation, centrifugation protocol \#1, centrifugation protocol \#2), and phase (upper, lower phase, the apparently differing aqueous phase was not included to allow a better interpretation concerning the main question i.e. differences between the upper and the lower half of the tissue phase within the syringes) as well as the interaction centrifugation ${ }^{\star}$ phase. $P$-values $<0.05$ were considered significantly different. 


\section{Results}

\section{Qualitative analysis of SVC after various processing}

Neither sedimentation nor mild or harsh centrifugation impacted the ASC content of the lower half of the tissue phase compared to the upper half within a fatty cylinder.

Analysis of CD45-positive cells revealed that the cells in the aqueous phase, if present, consisted mainly of immune cells (Figure 1A). Tissue content of immune cells did not change with any processing. These data indicate that those immune cells were not tightly associated with the tissue, probably were from peripheral blood contamination, and could be removed from the aspirate either by washing or by sedimentation and centrifugation and subsequent removal of the aqueous phase. Notably, the majority of the immune cells still remained in the tissue phase as a normal constituent of human adipose tissue, where approximately $40 \%$ of the SVCs were CD45-positive cells (Figure 3B).

Interestingly, there was a significant ( $p=0.002$, Figure $3 \mathrm{C}$ ) increase of endothelial cells in the lower tissue phase compared to the upper phase, and but remarkably, not of ASCs. Since in the multifactorial ANOVA no interaction terms indicated statistical significances, this enrichment occurred independently from the separation process of the phases (sedimentation vs. centrifugation) as well as the preceding washing procedure.

As shown in figure 1, the CD34-positive, CD45 (hematopoietic cell)-negative population, which was identical with the CD90-positive population, not shown) separated into CD105-high, CD73-low and CD105-low, CD73- high subpopulation. Additional analyses using CD31-FITC and CD144-PE from Serotec and Beckman Coulter, respectively, showed that the CD105-high, CD73-low cells were positive for CD144 and CD31, identifying them as endothelial cells, whereas CD105-low, CD73-high cells were negative for CD144 and CD31, identifying them as the progenitor cell fraction, hereafter referred to as ASCs in this manuscript.

Quantitative analysis of SVC of human adipose tissue aspirates after various processing

The washing procedure tested here markedly increased the volume of the adipose tissue phase within the syringe by reducing the aqueous phase from approximately $35 \%$ to $10 \%$ of the syringe volume, leading to more homogenous samples. The aqueous phase was essentially devoid of any cells, while in the unwashed samples $5-10 \%$ of the cells of a syringe were found in the aqueous phase (Figure $2 \mathrm{~A}$ ), which in the subsequently centrifuged syringes were pelleted at the bottom.

\section{Discussion}

In contrast to the results of Allen et. al, who radically isolated the monocular cell population from the stromal vascular fraction by density gradient centrifugation using a Histopaque 1077 (SigmaAldrich) and subsequent ASC isolation by magnetic cell separation using a commercially available lineage depletion kit [23], we used flow cytometry according to standard procedures, whereby a more specific determination of all different cell types in the stromal vascular fraction can be made. As an important side finding, we identified CD105 as an endothelial cell marker within human adipose tissue, while CD90 was expressed on all CD34-positive cells. This is of particular importance given the fact that these markers are broadly recognized as ASC markers, which may lead to misinterpretations of results when CD105 and CD90 are used as markers for investigating cell populations in

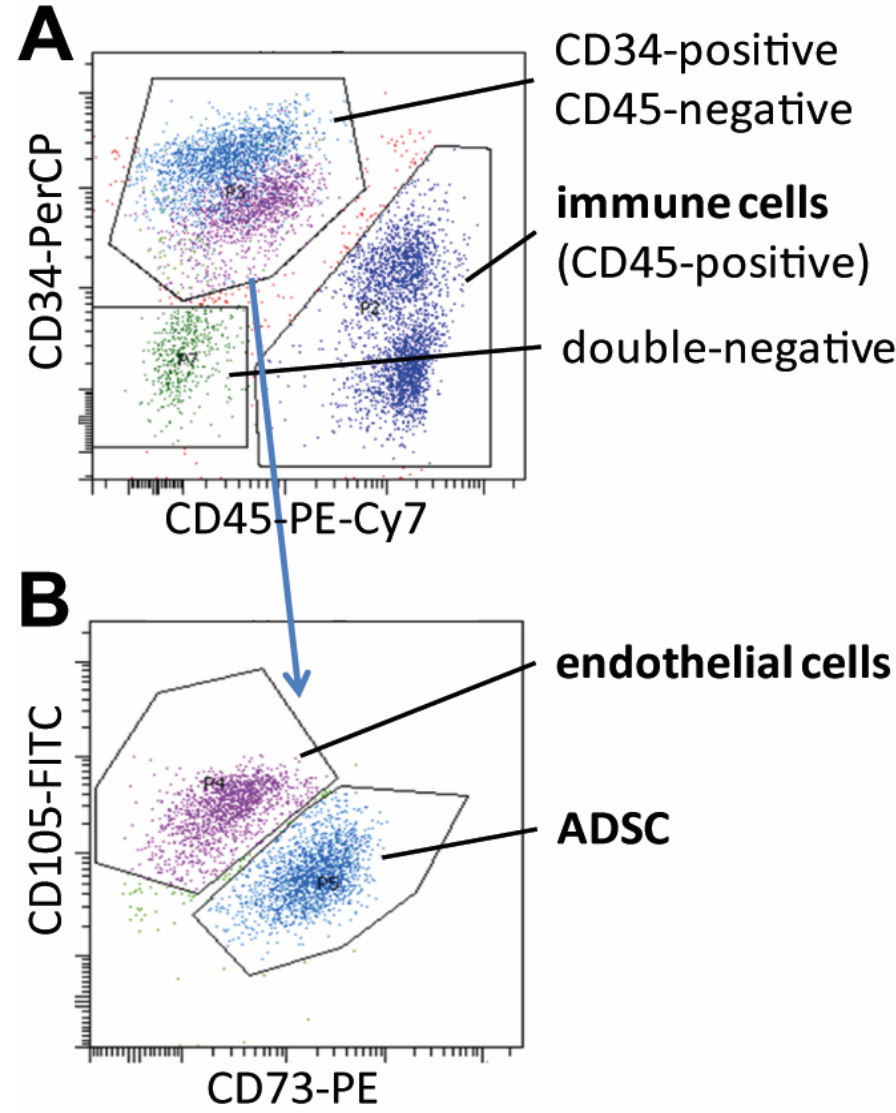

Figure 1. Identification of ASCs, immune cells, and endothelial cells in the stromal vascular cell fraction from adipose tissue aspirates. A. Identification of immune cells (CD45positive), progenitor and endothelial cells (CD34-positive), and other mesenchymal cells (double negative) within stromal vascular cells by flow cytometry. B. Subdivision of the CD34-positive, CD45-negative population by differential expression of CD105 and CD73. Typical dot blots of fluorescence intensities obtained from cells stained with indicated fluorescence dye-conjugated antibodies are shown.

human adipose tissue. If and how our findings relate to the described CD13-positive population of SVC as described by Bourin et al. [31] remains to be elucidated.

Our study unexpectedly showed no enrichment of ASCs in the lower fatty cylinder, and naturally not in the upper fatty cylinder either. Regarding the findings of Allen et. al that the high-density fraction of the fatty cylinder leads to a better fat graft take, we assume that this is not due to ASC enrichment as this was not verified in our study, but probably due to endothelial cell enrichment, since our study demonstrated the enrichment of this type of cells in the lower fatty cylinder. This assumption is strengthened by previous findings that endothelial cells are capable of dedifferentiating into progenitor cells that can give rise to adipocytes $[27,28]$ and endothelial cells improve adipose tissue graft survival by increasing vascularization [29]. It might be valuable to verify the findings of this study by investigating the role of endothelial cells in the take of autologous fat grafts.

Despite the fact that ASCs are capable of expressing VEGF during hypoxia which can lead to additional endothelial cells and improved vascularization $[30,31]$, it would be interesting to investigate whether enriching fat grafts with endothelial cells is superior to enrichment with ASCs regarding enhanced survival.

The washing procedure implemented was useful as it was shown that in the washed group, the volume of fat in all samples was very 
similar. This enabled precise results as all measurement procedures were based on similar cell numbers. These results indicate that the washing procedure described here is sufficient to remove any cells released from tissue by the aspiration process and those stemming from blood contamination and lead to more precise samples. The washing procedure, however, significantly increased the cell number per volume ( $p=0.015$, Figure 2B) indicating that after washing the tissue phase is more tightly packed and the water content is reduced, while there was trend toward increased cell density after centrifugation as compared to sedimentation, particularly in the washed samples, but without statistical significance ( $p=0.156$, Figure $2 \mathrm{~B}$ ). In addition, $10 \%$ of ASCs was found in the aqueous phase of the non-washed samples (Figure 3A). Washing replaces centrifugation in that no immune cells were found in the aqueous phase of the washed group samples, thereby demonstrating that the washing procedure removes the immune cells from peripheral blood as effectively as centrifugation.

Figure 3A shows a noticeable percentage of SVC in the aqueous phase of the non-washed samples in which $10 \%$ of the ASCs were detected. This reveals the aqueous phase as an important factor to possibly positively enhance the graft take rate. Since the aqueous phase is most often dispatched to obtain more homogeny samples it would be interesting to investigate if the presents of the aqueous phase enhances
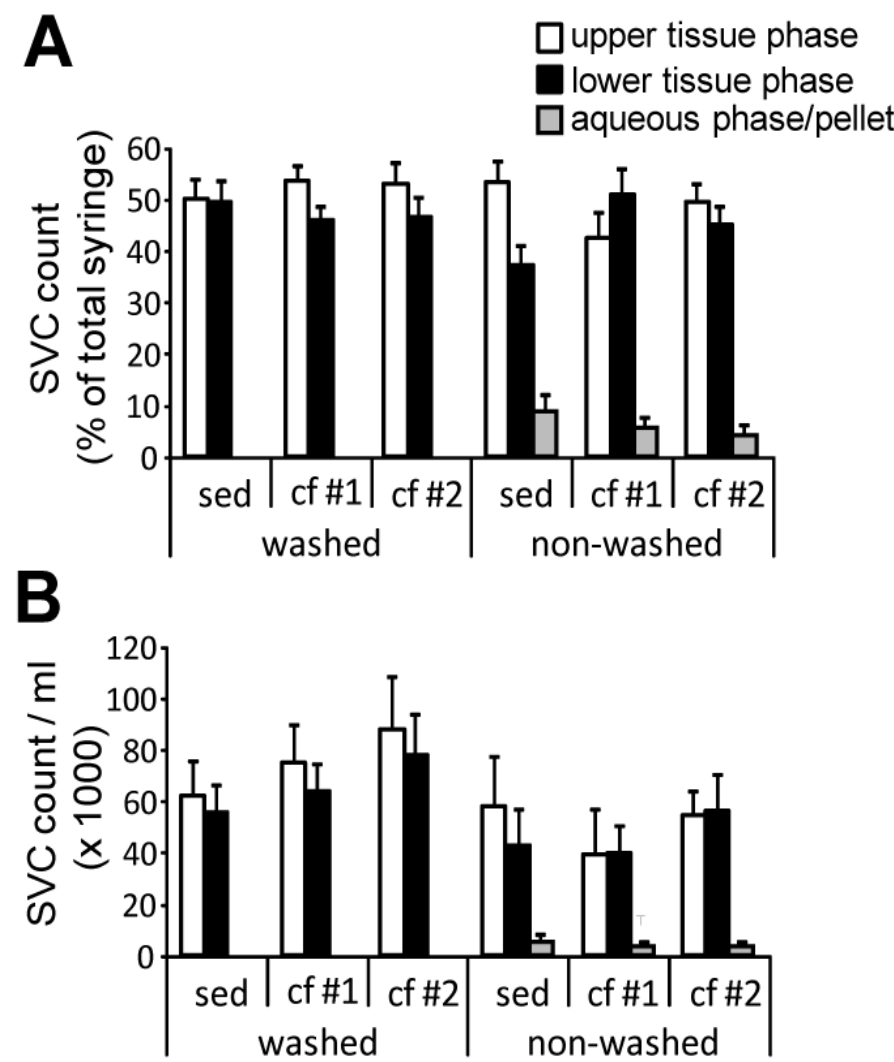

Figure 2. Stromal vascular cell counts in the different phases of sedimented and centrifuged human adipose tissue aspirates. Human adipose tissue aspirates $(\mathrm{n}=10)$ were separated by sedimentation (sed), and mild and harsh centrifugation ( $\mathrm{cf} \# 1$ and $\mathrm{cf} \# 2$, respectively) as described in detail in the Material and Methods section. Stromal vascular cells (SVC) were isolated from the upper and lower half of the tissue phase as well as the aqueous phase on the bottom of the syringe together with pelleted cells and counted. A. SVC numbers of the different phases related to the total SVC number within the syringes. Diagram shows mean \pm SE. There were no statistical significances between the different tissue phase groups according to multifactorial ANOVA. B. SVC numbers per $\mathrm{ml}$ of the respective phases. Diagram shows mean and SEM. Statistical significances according to multifactorial ANOVA: $p=0.015$ for washed vs. non-washed. No other significant differences between the tissue phase groups were determined.
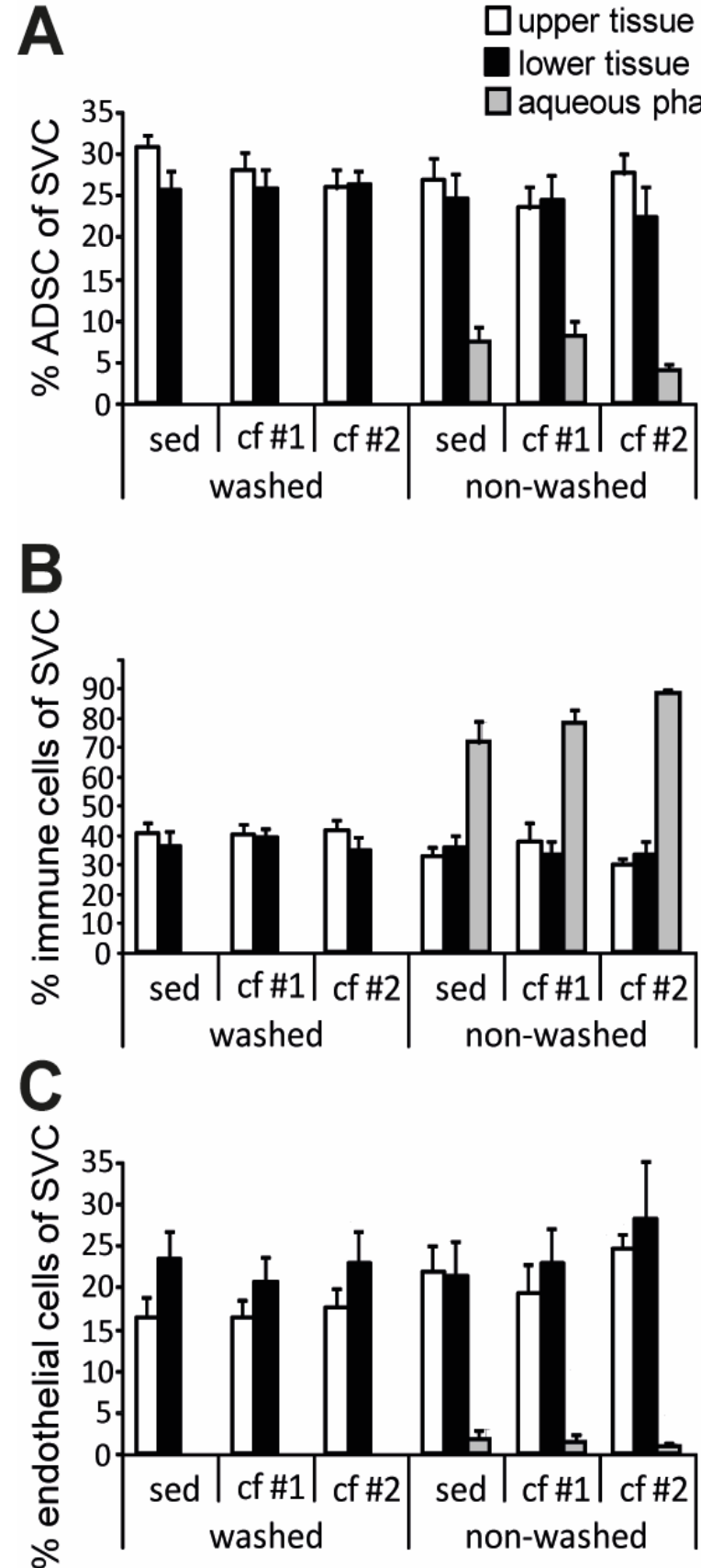

Figure 3. Proportion of ASCs and endothelial cells in the two phases of sedimented and centrifuged human adipose tissue aspirates. Human adipose tissue aspirates $(\mathrm{n}=10)$ were separated by sedimentation (sed), or mild and harsh centrifugation (CF 1 and $\mathrm{CF} 2$, respectively). Stromal vascular cells (SVC) were isolated from the upper and lower half of the tissue phase and the proportions of ASCs (A) and endothelial cells (C) were determined by flow cytometry. The diagrams show mean and SEM of the percentage of SVC of indicated cell types. Asterisks indicate a significantly different number of endothelial cells in the lower tissue phase compared to the upper tissue phase according to multifactorial $\operatorname{ANOVA}(* * p \leq 0.01)$.

the take rate due to the presents of up to $10 \%$ ASC or downgrades the graft take rate due to in-homogeny.

\section{Conclusion}

Innovative strategies are needed for improved delivery and retention of SVCs for cell assisted lipotransfer. In contrast to results of Allen et al., authors found that centrifuging fat aspirates causes 
endothelial cell enrichment, but not ASC enrichment. The better graft take described by Allen et al. is probably not due to ASC enrichment, but rather due to endothelial cell enrichment in the lower part of the fatty cylinder.

Discarding the aqueous phase, even if it contains no adipocytes at all, might be a potential "waste" if an enriched ASC cell count is the goal.

\section{References}

1. Ersek RA, Chang P, Salisbury MA (1998) Lipo layering of autologous fat: an improved technique with promising results. Plast Reconstr Surg 101: 820-826. [Crossref]

2. Champaneria MC, Wong WW, Hill ME, Gupta SC (2012) The evolution of breast reconstruction: a historical perspective. World J Surg 36: 730-742. [Crossref]

3. Peer L (195) Loss of weight and volume in human fat grafts: with postulation of a "cell survival theory." Plast Reconstr Surg 5:217-230.

4. Kesselring UK, Meyer R (1978) A suction curette for removal of excessive local deposits of subcutaneous fat. Plast Reconstr Surg 62: 305-306. [Crossref]

5. Kesselring UK (1987) Suction lipectomy of the neck. Plast Reconstr Surg 79: 489. [Crossref]

6. Illouz YG (1983) Body contouring by lipolysis: a 5-year experience with over 3000 cases. Plast Reconstr Surg 72: 591-597. [Crossref]

7. Coleman SR (1995) Long-Term Survival of Fat Transplants: Controlled Demonstrations. Aesthet Plast Surg 19: 421-425. [Crossref]

8. Gutowski KA (2009) Current Applications and Safety of Autologous Fat Grafts: A Report of the ASPS Fat Graft Task Force. Plast Reconstr Surg 124: 272-280. [Crossref]

9. Pu LL (2012) Towards more rationalized approach to autologous fat grafting. J Plast Reconstr Aesthet Surg 65: 413-419. [Crossref]

10. Sommer B, Sattler G (200) Current Concepts of Fat Graft Survival: Histology of Aspirated Adipose Tissue and Review of the Literature. Dermatol Surg 26:1159-1166. [Crossref]

11. Nishimura T, Hashimoto H, Nakanishi I, Furukawa M (2000) Microvascular angiogenesis and apoptosis in the survival of free fat grafts. Laryngoscope 110: 13331338. [Crossref]

12. Guerrerosantos J, Gonzalez-Mendoza A, Masmela Y, Gonzalez MA, Deos M, et al. (1996) Long-term survival of free fat grafts in muscle: an experimental study in rats. Aesthetic Plast Surg 20: 403-408. [Crossref]

13. Zuk PA, Zhu M, Mizuno H, Huang J, Futrell JW, et al. (2001) Multilineage Cells from Human Adipose Tissue: Implications for Cell-Based Therapies. Tissue Eng 7:211-228. [Crossref]

14. Yoshimura K, Sato K, Aoi, Kurita M, Hirohi T, et al. (2008) Cell-Assisted Lipotransfer for Cosmetic Breast Augmentation: Supportive Use of Adipose-Derived Stem/Stromal Cells. Aesthet Plast Surg 32: 48-55. [Crossref]

15. Kølle SF, Fischer-Nielsen A, Mathiasen AB, Elberg JJ, Oliveri RS, et al. (2013) Enrichment of Autologous Fat Grafts with Ex-Vivo Expanded Adipose Tissue-Derive Stem Cells for Graft Survival: A Randomised Placebo-Controlled Trial. Lancet 382: 1113-1120. [Crossref]

16. Tiryaki T, Findikli N, Tiryaki D (2011) Staged Stem Cell-Enriched Tissue (SET) Injections for Soft Tissue Augmentation in Hostile Recipient Areas: A Preliminary Report. Aesthet Plast Surg 35:965-971. [Crossref]
17. Tanikawa DY, Aguena M, Bueno DF Passos-Bueno MR, Alonso N (2013) Fat Grafts Supplemented with Adipose-Derived Stromal Cells in the Rehabilitation of Patients with Craniofacial Microsomia. Plast Reconstr Surg 132:141-152. [Crossref]

18. Zhu M, Zhou Z, Chen Y, Schreiber R, Ransom JT, et al. (2010) Supplementation of Fa Grafts with Adipose-Derived Regenerative Cells Improves Long-Term Graft Retention. Ann Plast Surg 64:222-228. [Crossref]

19. von Heimburg D, Zachariah S, Heschel I, Kühling H, Schoof H, et al. (2001) Human preadipocytes seeded on freeze-dried collagen scaffolds investigated in vitro and in vivo. Biomaterials 22: 429-438. [Crossref]

20. Carvalho PP, Gimble JM, Dias IR, Gomes ME, Reis RL (2013) Xenofree Enzymatic Products for the Isolation of Human Adipose-Derived Stromal/stem Cells. Tissue Eng Part C Methods 19:473-478. [Crossref]

21. Aronowitz JA, Lockhart RA, Hakakian CS, Birnbaum ZE (2016) Adipose Stromal Vascular Fraction Isolation: A Head-to-Head Comparison of 4 Cell Separation Systems \#2. Ann Plast Surg 77:354-362. [Crossref]

22. Dos-Anjos Vilaboa S, Navarro-Palou M, Llull R (2014) Age Influence on Stromal Vascular Fraction Cell Yield Obtained from Human Lipoaspirates. Cytotherapy 16:1092-1097. [Crossref]

23. Allen RJ Jr, Canizares O Jr, Scharf C, Nguyen PD, Thanik V, et al. (2013) Grading lipoaspirate: is there an optimal density for fat grafting? Plast Reconstr Surg 131: 3845. [Crossref]

24. Galiè M, Pignatti M, Scambi I, Sbarbati A, Rigotti G (2008) Comparison of Different Centrifugation Protocols for the Best Yield of Adipose-Derived Stromal Cells from Lipoaspirates. Plast Reconstr Surg 122:233e-234e. [Crossref]

25. Kurita M, Matsumoto D, Shigeura T, Sato K, Gonda K, et al. (2008) Influences of Centrifugation on Cells and Tissues in Liposuction Aspirates: Optimized Centrifugation for Lipotransfer and Cell Isolation. Plast Reconstr Surg 121:1033-1043. [Crossref]

26. Zeyda M, Farmer D, Todoric J, Aszmann O, Speiser M, et al. (2007) Human adipose tissue macrophages are of an anti-inflammatory phenotype but capable of excessive pro-inflammatory mediator production. Int J Obes (Lond) 31:1420-1428. [Crossref]

27. Tran KV, Gealekman O, Frontini A, Zingaretti MC, Morroni M, et al. (2012) The vascular endothelium of the adipose tissue gives rise to both white and brown fat cells. Cell Metab 15: 222-229. [Crossref]

28. Wosnitza M, Hemmrich K, Groger A, Gräber S, Pallua N (2007) Plasticity of Human Adipose Stem Cells to Perform Adipogenic and Endothelial Differentiation. Differentiation 75:12-23. [Crossref]

29. Luo X, Cao W, Xu H, Wang L, Zhang Z, et al. (2015) Coimplanted Endothelial Cells Improve Adipose Tissue Grafts' Survival by Increasing Vascularization. J Craniofac Surg 26:358-364. [Crossref]

30. Aoki S, Toda S, Sakemi T, Sugihara H (2003) Coculture of Endothelial Cells and Mature Adipocytes Actively Promotes Immature Preadipocyte Development in Vitro. Cell Struct Funct 28: 55-60. [Crossref]

31. Rehman J, Traktuev D, Li J, Merfeld-Clauss S, Temm-Grove CJ, et al. (2004) Secretion of Angiogenic and Antiapoptotic Factors by Human Adipose Stromal Cells. Circulation 109:1292-98. [Crossref]

32. Bourin P, Bunnell BA, Casteilla L, Dominici M, Katz AJ, et al. (2013) Stromal Cells from the Adipose Tissue-Derived Stromal Vascular Fraction and Culture Expanded Adipose Tissue-Derived Stromal/stem Cells: A Joint Statement of the International Federation for Adipose Therapeutics and Science (IFATS) and the International Society for Cellular Therapy (ISCT). Cytotherapy 15: 641-48. [Crossref]

Copyright: (C2018 Lutfi D. This is an open-access article distributed under the terms of the Creative Commons Attribution License, which permits unrestricted use, distribution, and reproduction in any medium, provided the original author and source are credited. 